\title{
Survey to Inform the Development of an Online Support System for Higher Education Students
}

-Higher Education and Online Support

\author{
Rhianna Goozée ${ }^{1}$, Marietta Papadatou-Pastou ${ }^{2 *}$, Elizabeth Barley ${ }^{3}$, Mark Haddad4, \\ Patapia Tzotzoli 5,6
}

${ }^{1}$ Independent Scholar, London, UK

${ }^{2}$ School of Education, National and Kapodistrian University of Athens, Athens, Greece

${ }^{3}$ Florence Nightingale Faculty of Nursing and Midwifery, King's College London, London, UK

${ }^{4}$ Interim Head of School, Human and Social Sciences and Professor of Health and Wellbeing, University of West London, London, UK

${ }^{5}$ Private Practice at Bank and Harley Street, London, UK

${ }^{6}$ iConcipio Ltd., London, UK

Email: ^mpapadatou@primedu.uoa.gr, rhianna.goozee@gmail.com, elizabeth.barley@kcl.ac.uk, mark.haddad.1@city.ac.uk,

patapia@iconcipio.com

How to cite this paper: Goozée, R., Papadatou-Pastou, M., Barley, E., Haddad, M. and Tzotzoli, P. (2018) Survey to Inform the Development of an Online Support System for Higher Education Students. Health, 10, 351-364.

https://doi.org/10.4236/health.2018.103028

Received: February 5, 2018

Accepted: March 24, 2018

Published: March 27, 2018

Copyright $\odot 2018$ by authors and Scientific Research Publishing Inc. This work is licensed under the Creative Commons Attribution International License (CC BY 4.0).

http://creativecommons.org/licenses/by/4.0/

\section{(c) (i) Open Access}

\begin{abstract}
An increasing number of higher education students face mental health difficulties, but the universities' student support services (SSS) struggle to meet demand with limited resources. Web-based alternatives hold promise as a novel medium through which students could access support. Online interventions appear to be effective and may therefore provide a cost-effective alternative, relieving some of the burden on struggling SSS. This paper presents results from an explorative survey of 61 students questioned about their opinion of online support systems. The majority of students indicated that they would use such a system and that it should be interactive and personalized, focusing on time and money management, relaxation exercises, and building social skills. Future directions towards the development of such a system are discussed.
\end{abstract}

\section{Keywords}

Online Intervention, Mental Health, Study Skills, Students, Well-Being, Higher Education

\section{Introduction}

University life provides opportunities for young adults to develop academically and personally [1]. It is also associated with various challenges, including exam 
stresses, financial concerns, and coping with increased independence [2]. In the $\mathrm{UK}$, increasing numbers of students declare a mental health difficulty (i.e., either a diagnosis of a mental health condition or experience of symptoms of poor mental health such as anxiety or depression) on entry to university [3], and $18 \%$ of Scottish students surveyed either have been diagnosed with or identify as having a mental health problem of any kind [4]. Stress, anxiety and depression have also been reported amongst Greek university students [5]. Further stressors affect large numbers of students, including stress related to exams (90.5\%) and deadlines (83.3\%) [3]. Such difficulties affect academic success and may lead to unhealthy lifestyles and behaviors, including binge drinking and smoking [2] or internet addiction [6]. Furthermore, true need may be greater than reported as many students are reluctant to seek support [4] [7].

While students' psychological and study skills support needs are apparently increasing, resources available for university student support services (SSS) are decreasing, reflecting the general global economic trend [8]. As a specific example, public funding from the UK government's department for Business, Innovation and Skills (BIS) is predicted to be cut by up to 30\% between 2014-2015 and 2017-2018 [9]. Such cuts are likely to affect SSS, meaning that they struggle to meet demand. Moreover, the counselor-student ratio is oftentimes enormous, namely 1 to 3500 and 1 to 7500 for the SSS at the University of Piraeus and the University of Crete, both in Greece, respectively [7]. It is therefore imperative that SSS are restructured, and alternative methods of support are urgently needed to ensure universities can effectively optimize their resources to meet their pastoral role. Doing so may reduce student dropout, increase annual student intake, and improve positions in rankings.

Within this difficult context, one recommendation from the Royal College of Psychiatrists (RCP) suggests self-help programmes, such as web-based interactive cognitive-behavioral therapy (CBT), should be used to support students [8]. Whilst face-to-face counseling should be prioritized for those with greatest need, web-based self-help could support those with less severe needs, reducing the burden on SSS.

In recent years, several web-based systems offering psychological support have become available [10]. Patients and their families can use these to seek information, practice self-help strategies, track their wellbeing, and in some cases communicate with other users via online support groups and forums. Many of these systems, such as BigWhiteWall, NHS Silvercloud, Beating the Blues, and Fearfighter, are designed for the general population and there is considerable support for their effectiveness [11]. Where web-based CBT is compared with face-to-face CBT, there appear to be similar benefits for the two modes of delivery, and these are maintained in the long term [11]. Such systems may also provide support to hard-to-engage groups, such as those with anxiety disorders who may not otherwise receive specialist support [12]. Furthermore, their use is associated with reduced personal perception of stigma related to one's mental illness [13]. 
Therefore, there is evidence that web-based CBT is effective, and this has been supported by studies of the technique implemented within routine clinical settings [14]. However, these studies have been geared to the general population and there is limited literature regarding existing internet-based support systems specifically designed for higher education (HE) students. Future research will need to address the effectiveness of such systems, as well as engagement and reach with this population.

One system currently on offer by some higher education institutions (HEI) for the support of their students is "CALM" (Computer Aided Lifestyle Management). However, this is restricted to use within one HEI (University College Cork), and evidence of its feasibility, effectiveness or students' satisfaction has not yet been published. Another example is "Students Against Depression", which is an information website run by students offering advice on depression, anxiety and suicidal thoughts, as well as tools and strategies for self-help. Again, no research is yet available to support the efficacy of this website. As this overview suggests, there are limited online systems offering evidence-based therapeutic interventions for students experiencing mental health problems, and there has been little investigation so far into their effectiveness. To the best of our knowledge, no previous systematic reviews of online systems designed specifically for HE students have been conducted. Furthermore, the systems that are designed for HE students do not address study skill problems, which may also influence academic achievement, as well as the psychological wellbeing of students. Given the effectiveness of web-based CBT in the general population [11], there is considerable hope that such systems may be useful to meet the needs of students experiencing psychological difficulties, easing the strain on SSS.

This paper presents findings from an online HEI student survey. Given the potential for web-based solutions to meet student's support needs, we aimed to gain end-user views on students' support needs, as well as on the format and functioning of a proposed online support system.

\section{Material and Methods}

We administered an online survey to 61 undergraduate and postgraduate university students at King's College London from the Waterloo campuses between February and April 2012. A convenience sample of students was recruited by handing out fliers on the university campus with participating students offered the opportunity to win a prize of a holiday. The survey contained seven questions regarding potential difficulties faced by students at university and views on online support systems (Appendix A).

The questions addressed the design and content features for a proposed online support system. The features investigated were chosen based on currently available online support systems, as well as a consideration of the particular needs of students. Where appropriate, research from the literature informed the choices for proposed system features. For example, 2D video graphics were proposed 
based on the Cognitive Theory of Multimedia Learning [15] [16], which promises a more effective way to deliver content, as well as ensuring that material is accessible and engaging. We also suggested a degree of personalisation of the system based on research that suggests personalised products elicit greater emotional investment and therefore may support increased use [17] [18].

Following data collection, data from open-ended and closed questions were explored using descriptive statistics.

\section{Results}

\subsection{Identified Difficulties}

Several responses were given regarding difficulties faced by university students (Table 1). These could be grouped into three broad categories: 1) time management/work load, e.g. "work", "pressure", "deadlines", “exams"; 2) social life, e.g. "making friends", "life"; and 3) finances, e.g. "money". The broad term "stress" was most commonly reported, but we suggest this is a product of the other difficulties cited, rather than a difficulty in itself.

\subsection{Use of Online Support Systems}

Six respondents (9.8\%) were unsure, reporting that they would "maybe" use an online system if they faced difficulties at university. Some respondents reported that they would not use such a system (14.8\%), citing several reasons, including that time could be better spent: “...it's likely to be work stress so I'd rather spend my time doing the work"; and that it would be too impersonal: "...it's a very impersonal and passive way to learn". However, the majority of respondents stated that they would use an online support system if they faced difficulties at university $(75.4 \%)$.

Table 1. Difficulties faced by university students identified by survey respondents.

\begin{tabular}{ccc}
\hline Difficulty faced & No. of respondents & \% of respondents \\
\hline Stress & 41 & 68.3 \\
Time management & 34 & 56.7 \\
Making friends & 28 & 46.7 \\
Work & 16 & 26.7 \\
Money & 13 & 21.7 \\
Life & 10 & 16.7 \\
Pressure & 8 & 13.3 \\
Deadlines & 7 & 11.7 \\
Exams & 6 & 10.0 \\
Family & 5 & 8.3 \\
\hline
\end{tabular}

*"Life" was mostly reported within the context of a work-life balance. Total percentage $>100 \%$ due to multiple responses. 
We also presented the names of several currently available online support programmes: Mood Gym, CALM, Beat the Blues, Living life to the full, and Fear fighter. Very few respondents had heard of or accessed these systems. Two respondents had heard of Mood Gym, only one of whom had accessed the system. The majority of respondents had never heard of or accessed any online support systems (95.1\%). This highlights the need for the developers of support systems to ensure that students are aware of support available to them, working with HEI to ensure students know about the systems and are able to access them.

\subsection{Features and Functionality}

We asked respondents which they preferred of a list of features that an online system could possess to help users develop skills to address their difficulties (Table 2). The most popular feature was signposting to personally relevant information and techniques (61\%). Furthermore, learning techniques to manage difficulties (via either written information: 56\%; or animated videos: 56\%) appears to be more important to respondents than understanding the difficulties themselves (written information: $37.7 \%$; animated videos: $36.1 \%$ ).

We also investigated the preferred characteristics of a narrator or character used to convey information in the online system. We wished to investigate whether respondents had preferences for narrator characteristics that might influence engagement with the proposed system. Respondents preferred a real female character $(42.1 \%)$, followed by an animated character $(33.3 \%)$, and least preferred a real male character $(24.6 \%)$. If an animated character were used, more respondents would prefer it to be human-like (60.7\%) as opposed to cartoon-like (39.3\%). Respondents also preferred a female voice (53.7\%) to narrate techniques as opposed to a male voice (46.3\%).

Respondents were asked a further question about specific features that could be included in an online support system (Table 3). The most popular of these was a tool to assess which techniques are relevant to the user and direct them to

Table 2. Number of respondents who would prefer proposed format of contents for an online system offering support.

\begin{tabular}{lcc}
\hline \multicolumn{1}{c}{ Feature } & No. of respondents & \% of respondents \\
\hline $\begin{array}{l}\text { Signposting to personally-relevant information } \\
\text { and techniques }\end{array}$ & 37 & 60.7 \\
$\begin{array}{l}\text { Written information about techniques for } \\
\text { managing difficulties }\end{array}$ & 34 & 55.7 \\
$\begin{array}{l}\text { Animated videos demonstrating techniques } \\
\text { Ability to browse freely through all information } \\
\text { and techniques demonstrated on the site }\end{array}$ & 34 & 54.1 \\
$\begin{array}{l}\text { Written information to help make sense of } \\
\text { difficulties }\end{array}$ & 33 & 37.7 \\
$\begin{array}{l}\text { Animated videos to help make sense of } \\
\text { difficulties }\end{array}$ & 23 & 36.1 \\
\hline
\end{tabular}

Total percentage $>100 \%$ due to multiple responses. 
Table 3. Desirability of proposed features of an online support system.

\begin{tabular}{lcc}
\hline \multicolumn{1}{c}{ Feature } & No. of respondents & \% of respondents \\
\hline $\begin{array}{l}\text { A questionnaire to direct the individual to } \\
\text { personally-relevant techniques }\end{array}$ & 46 & 75.4 \\
$\begin{array}{l}\text { The ability to monitor mood and progress over } \\
\text { time }\end{array}$ & 41 & 67.2 \\
$\begin{array}{l}\text { Tailor-made workshops } \\
\begin{array}{l}\text { A short screening questionnaire to assess whether } \\
\text { the individuals' difficulties can be helped by the } \\
\text { program }\end{array}\end{array}$ \\
$\begin{array}{l}\text { A personal space within which to keep track of } \\
\text { personally-relevant information, techniques and }\end{array}$ \\
$\begin{array}{l}\text { activities } \\
\begin{array}{l}\text { The option to make a personal plan, in order to } \\
\text { set 'homework' and deadlines }\end{array}\end{array}$ \\
$\begin{array}{l}\text { The option to receive reminders about personal } \\
\text { plan deadlines }\end{array}$ \\
$\begin{array}{l}\text { A diary space within which to keep notes about } \\
\text { which techniques are helpful and how often they } \\
\text { have been completed }\end{array}$
\end{tabular}

Total percentage $>100 \%$ due to multiple responses.

those resources. The ability to track progress and the inclusion of tailor-made workshops were also chosen by many respondents.

\subsection{Access and Resources}

Our final question addressed how respondents might access the system and the inclusion of further resources (Table 4). The ability to access the system on a mobile phone (68.9\%) was more popular than access via other mobile devices, such as iPads (37.7\%). Several signposting resources were suggested, with referral to university SSS or professional help being the most popular (65.6\%), followed by a peer-support forum (59.0\%).

\section{Discussion}

This paper details results from an online HEI student survey of university students regarding their views about online support systems. The results suggest enthusiasm for such a system, with most students suggesting they would use available online support if facing difficulties. It is clear that they would like the system to be interactive and personalised, focusing on time and money management, and building social skills. The feedback provided by the students has informed further development of the proposed online support system such that it meets the needs and preferences of its intended users [19]. This was further supported by a review of currently available systems to address continued unmet need and desirable features [10]. 
Table 4. Desirability of given capabilities of an online support system.

\begin{tabular}{lcc}
\hline \multicolumn{1}{c}{ Capability } & No. of respondents & \% of respondents \\
\hline $\begin{array}{l}\text { Function as a mobile application } \\
\begin{array}{l}\text { Providing information about university student } \\
\text { support services and professional help }\end{array}\end{array}$ & 42 & 68.9 \\
$\begin{array}{l}\text { Providing a forum to discuss difficulties with } \\
\text { other students }\end{array}$ & 36 & 65.6 \\
$\begin{array}{l}\text { Website troubleshooting } \\
\text { Video testimonials }\end{array}$ & 23 & 59.0 \\
$\begin{array}{l}\text { Function on mobile devices such as the iPad } \\
\text { Providing recommendations for self-help books }\end{array}$ & 23 & 37.7 \\
\hline
\end{tabular}

Total percentage $>100 \%$ due to multiple responses.

Respondents highlighted challenges in three main areas: time-management/work; social life; and finance. The majority of participants identified the non-specific term "stress", which we take to be a consequence of these other difficulties rather than a difficulty/cause in itself. Other studies have highlighted similar concerns amongst university students, for instance interpersonal relationships [7] [20] and money worries [4] [7]. Consequently, we recommend that online interventions for university students chiefly focus on: 1) relaxation exercises; 2) time management techniques; 3) building social skills; and 4) money management. Such interventions focus primarily on problem-focused coping methods to help reduce stress [21], providing practical methods of coping where the causes of stress are under the control of the student. Social support in the form of information and advice seeking has indeed been found to predict psychological health in a sample of Greek university students [22]. The sample was recruited from both the School of Philosophy and the School of Physics and included both male and female students. Although cultural differences with college populations from other countries might be present, this study provides support for the generalizability of the techniques used by the system in a cross-cultural context. The addition of relaxation exercises provides an emotion-focused coping technique for situations where the cause of stress may not be under the control of the students but they require a strategy to cope with the resultant stress [23].

We propose the use of an online system specifically designed for students to support them to cope with and manage the difficulties they have identified. While a number of other systems are already available, these were not known or used by the students we surveyed. Importantly, many of these systems are not designed specifically for students, which might explain why students are unaware of them.

The respondents showed a preference for practical action (i.e., techniques to deal with difficulties) over theoretical information about their problems. They also emphasized a desire to be able to browse freely through other resources. It is important that an online self-help system incorporates effective signposting to 
other resources where appropriate. This fits with previous surveys of student views that have highlighted concerns about the wealth of mental health information on the internet, which suggests filtering and signposting for students would be useful [24]. Our respondents suggested that they would like to see links to further support and resources that provide some kind of interactivity with others, such as peer support forums, university support services, and professional help, as opposed to more self-help via a different medium, such as books. Personalisation was also a key concern of the respondents, who also showed a preference for packages of personally-relevant techniques put together using a questionnaire, being able to monitor their progress, and having tailor-made workshops.

It is interesting that while the majority of students $(75.4 \%)$ indicated that they would use an online support system, almost none had heard of or used systems that are currently available. This indicates how important it is to market support systems to their target audiences, such that they are aware of the support available to them. The system that is being developed by the authors will be marketed to students in two ways. First, the system will be marketed to universities, who will incorporate it into their SSS provisions. They will make students aware of the system through several routes, including fresher leaflets, email circulars, and their website. Second, we will also market the system directly to students via social media, student fairs, student groups such as the NUS, and healthcare professionals such as GPs. Given the high numbers of people using social media, particularly among younger adults [25], this route may be particularly important in reaching students requiring support for mental ill health.

Support systems designed for students should also take into account their specific preferences and needs, to ensure engagement with the available support systems. Consultation with HEI SSS was also conducted as this can further aid development of the system by incorporating the experience and knowledge of therapists and counsellors in these services. Taking these views into account is extremely important if students are to benefit from such systems. In addition to student preferences and needs, several evidence-based therapeutic models will be used to address the issues identified by the students. An expert clinical team has been consulted for the initial design of the system, and they have taken into account latest evidence of the effectiveness of online psychological support [26] [27]. The reduction and management of anxiety and depression will use techniques chosen based on previous research showing their effectiveness, for example cognitive behavioural therapy (CBT) [28] and behavioural activation [29]. Further details of the system can be found elsewhere [19] [30].

This survey provides some preliminary guidance for the development of a web-based student support system. It is limited by the small sample obtained from just one university, which may therefore not be representative of the wider population of HE students. Moreover, demographics such as gender and age were not recorded, and neither were any disabilities. It is possible that factors such as gender may impact the use of web-based support. Furthermore, some 
questions did not include the option "Other". This might have limited the responses of the respondents and did not give them the opportunity to provide further ideas and preferences. However, our results do support the concept of offering support in this format, and provide information regarding needs and preferences of the users to inform initial prototypes. This should be extended by research in larger samples of students, from a range of institutions, and by including analyses of subgroups to explore the potential effects of participant characteristics on use of and preferences for web-based support.

The results from this survey have guided the development of a new online multimedia intervention system under the trade name MePlusMe, which is designed to support students facing psychological difficulties in the form of mild to moderate symptoms of anxiety and depression, as well as study skills difficulties. The results of this survey provide some initial insight into the features and contents of an online support system for HE students, based on a survey of a small group of such students. Further research by our group will build on our findings. A proof-of-concept study invited students from five UK universities to test a demonstration of each part of the proposed system [19]. This study found that responses from students were largely positive, although some areas for improvement were highlighted. These results will further guide the development of the system and we have begun a feasibility study in September 2017 to evaluate the feasibility, acceptability, and potential effects of the interventions offered in MePlusMe in addressing mild to moderate psychological and study skills difficulties in HE students, as well as its content. A more in-depth feasibility study [30] and a subsequent randomised controlled trial (RCT) are to follow.

\section{Conclusion}

This survey provides early guidance in the development of an online support system for HE students. The survey suggests that HE students would welcome online support for the difficulties they face at university. The system must be designed to meet user preferences if it is to be attractive to students, and also must be both interactive and personal. The system should focus on time and money management, relaxation exercises, and building social skills, as identified by the students.

\section{Disclosure Statement}

MPP \& RG are pro bono Research Associates for iConcipio Ltd.; MH \& EB are pro bono members of the Academic Advisory Board for iConcipio Ltd.; PT is the founder and CEO of iConcipio Ltd.; iConcipio Ltd. is the developer of MePlusMe. No author has received any payment for this work to date. If the intervention is profitably commercialised and should any of the authors be employed at the time, then their profits will be in the form of a salary.

\section{Acknowledgements}

We would like to thank Liam Ennis who assisted in the initial organisation of 
survey data included in this report. We would also like to thank the KCL students who responded to the survey.

\section{Funding}

This work was supported by a private investor from a medical field.

\section{References}

[1] Giovazolias, T., Karademas, E. and Kalantzi-Azizi, A. (2008) Crossing Internal and External Borders. Practices for an Effective Psychological Counselling in the European Higher Education. Ellinika Grammata, Athens.

[2] El Ansari, W. and Stock, C. (2011) Feeling Healthy? A Survey of Physical and Psychological Wellbeing of Students from Seven Universities in the UK. International Journal of Environmental Research and Public Health, 8, 1308-1323. https://doi.org/10.3390/ijerph8051308

[3] Higher Education Statistics Agency (2014) HESA Online Information Service, Table 14. https://www.hesa.ac.uk/index.php?option=com_content\&view=article\&id=1897

[4] National Union of Students (2010) Silently Stressed: A Survey into Student Mental Wellbeing. http://www.nus.org.uk/PageFiles/12238/THINK-POS-REPORT-Final.pdf

[5] Papadioti, V. and Damigos, D. (2003) Psychosocial Needs and Adjustment of the University of Ioannina Students. Dodoni LB, 3, 231-262. (In Greek)

[6] Frangos, C.C., Fragkos, K.C. and Kiohos, A. (2010) Internet Addiction among Greek University Students: Demographic Associations with the Phenomenon, Using the Greek Version of Young's Internet Addiction Test. International Journal of Economic Sciences and Applied Research, 3, 49-74.

[7] Giovazolias, T., Leontopoulou, S. and Triliva, S. (2010) Assessment of Greek University Students' Counselling Needs and Attitudes: An Exploratory Study. International Journal for the Advancement of Counselling, 32, 101-116. https://doi.org/10.1007/s10447-010-9092-2

[8] Royal College of Psychiatrists (2011) The Mental Health of Students in Higher Education. Council Report CR166, London.

[9] Universities UK (2013) The Funding Challenge for Universities. Higher Education in Focus: New Horizons.

[10] Papadatou-Pastou, M., Goozee, R., Payne, E., Barrable, A. and Tzotzoli, P. (2017) A Review of Web-Based Support Systems for Students in Higher Education. International Journal of Mental Health Systems, 11, 59. https://doi.org/10.1186/s13033-017-0165-Z

[11] Andersson, G. and Titov, N. (2014) Advantages and Limitations of Internet-Based Interventions for Common Mental Disorders. World Psychiatry, 13, 4-11. https://doi.org/10.1002/wps.20083

[12] Kohn, R., Saxena, S., Levav, I. and Saraceno, B. (2004) The Treatment Gap in Mental Health Care. Bulletin of the World Health Organisation, 82, 858-866.

[13] Griffiths, K., Christensen, H., Jorm, A.F., Evans, K. and Groves, C. (2004) Effect of Web-Based Depression Literacy and Cognitive-Behavioural Therapy Intervention on Stigmatising Attitudes to Depression. The British Journal of Psychiatry, 185, 342-349. https://doi.org/10.1192/bjp.185.4.342

[14] Andersson, G. and Hedman, E. (2013) Effectiveness of Guided Internet-Based Cog- 
nitive Behavior Therapy in Regular Clinical Settings. Verhaltenstherapie, 23, 140-148. https://doi.org/10.1159/000354779

[15] Mayer, F. (2001) Multimedia Learning. Cambridge University Press, New York. https://doi.org/10.1017/CBO9781139164603

[16] Mayer, R.E. (2003) The Promise of Multimedia Learning: Using the Same Instructional Design Methods across Different Media. Learning and Instruction, 13, 125-139. https://doi.org/10.1016/S0959-4752(02)00016-6

[17] Mugge, R., Schoormans, J.P.L. and Schifferstein, H.N.J. (2009) Emotional Bonding with Personalised Products. Journal of Engineering Design, 20, 467-476. https://doi.org/10.1080/09544820802698550

[18] Fan, H. and Poole, M.S. (2006) What Is Personalization? Perspectives on the Design and Implementation of Personalization in Information Systems. Journal of Organizational Computing and Electronic Commerce, 16, 179-202. https://doi.org/10.1207/s15327744joce1603\&4_2

[19] Touloumakos, A.K., Goozée, R., Papadatou-Pastou, M., Barley, E., Haddad, M. and Tzotzoli, P. (2016) Online Support System for Students in Higher Education: Proof-of-Concept Study. Digital Health, 2, 1-24. https://doi.org/10.1177/2055207616655012

[20] Gallagher, R., Gill, A. and Sysko, H. (2000) National Survey of Counseling Center Directors, Alexandria, VA.

[21] Penley, J.A., Tomaka, J. and Wiebe, J.S. (2002) The Association of Coping to Physical and Psychological Health Outcomes: A Meta-Analytic Review. Journal of Behavioral Medicine, 25, 551-603. https://doi.org/10.1023/A:1020641400589

[22] Karademas, E.C. and Kalantzi-Azizi, A. (2004) The Stress Process, Self-Efficacy Expectations, and Psychological Health. Personality and Individual Differences, 37, 1033-1043. https://doi.org/10.1016/j.paid.2003.11.012

[23] Lazarus, R.S. and Folkman, S. (1984) Stress, Appraisal and Coping. Springer, New York.

[24] Chan, J.K.Y., Farrer, L.M., Gulliver, A., Bennett, K. and Griffiths, K.M. (2016) University Students' Views on the Perceived Benefits and Drawbacks of Seeking Help for Mental Health Problems on the Internet: A Qualitative Study. JMIR Human Factors, 3, e3. https://doi.org/10.2196/humanfactors.4765

[25] Ofcom (2017) Adults' Media Use and Attitudes: Report 2017. https://www.ofcom.org.uk/_data/assets/pdf_file/0020/102755/adults-media-use-att itudes-2017.pdf

[26] Corrigan, P. (2004) How Stigma Interferes with Mental Health Care. The American Psychologist, 59, 614-625. https://doi.org/10.1037/0003-066X.59.7.614

[27] van der Houwen, K., Schut, H., van den Bout, J., Stroebe, M. and Stroebe, W. (2010) The Efficacy of a Brief Internet-Based Self-Help Intervention for the Bereaved. Behaviour Research and Therapy, 48, 359-367. https://doi.org/10.1016/j.brat.2009.12.009

[28] Spek, V., Cuijpers, P.I.M., Nyklíček, I., Riper, H., Keyzer, J. and Pop, V. (2007) Internet-Based Cognitive Behaviour Therapy for Symptoms of Depression and Anxiety: A Meta-Analysis. Psychological Medicine, 37, 319-328. https://doi.org/10.1017/S0033291706008944

[29] Veale, D. (2008) Behavioural Activation for Depression. Advances in Psychiatric Treatment, 14, 29-36. https://doi.org/10.1192/apt.bp.107.004051

[30] Papadatou-Pastou, M., Goozée, R., Barley, E.A., Haddad, M. and Tzotzoli, P. (2015) 
Online Intervention, "MePlusMe", Supporting Mood, Wellbeing, Study Skills, and Everyday Functioning in Students in Higher Education: A Protocol for a Feasibility Study. Pilot and Feasibility Studies, 1, 34.

https://doi.org/10.1186/s40814-015-0029-8 


\section{Appendix A}

\section{Survey Questions}

1) What kind of difficulties are you aware that students may face while at university? (e.g. stress, time management, making friends). Please write in order of importance.

2) If you were facing any of these difficulties while at university, would you be interested in using an online system to help you develop skills to manage your difficulties more effectively? Please explain why yes or why no.

3) If you have heard or tried the following online support programs, please indicate what you liked and what you did not like for each of them.

- Mood Gym

- CALM

- Beat the Blues

- Living Life to the Full

- Fear Fighter

- Other, please specify

- If you have not heard or tried any of them, please write 'None of them' in the box

4) If you were using an online system to help you develop skills to address these difficulties, which of the following would you prefer? You may choose more than one answer.

- Written information to help me make sense of my feelings (e.g. what happens to me when I feel stressed);

- Written information about techniques that I can use to manage my difficulties more effectively;

- Animated videos to help me make sense of my difficulties (e.g. what happens to me when I feel stressed);

- Animated videos about techniques that I can use to manage my difficulties more effectively;

- To be able to browse freely all the different information and techniques available in the system;

- To be directed to information and techniques that are relevant to my personal circumstances.

5) If you were using an online system with animated videos to help you develop skills to address these difficulties, which of the following would you prefer? You may choose more than one answer.

- I would prefer the videos to use a real person, preferably a man;

- I would prefer the videos to use a real person, preferably a woman;

- I would prefer the videos to use an animated character;

- I would prefer the animated character of the videos to be as human as possible;

- I would prefer the animated character of the videos to be more cartoonish;

- I would like the narrator of the videos to have a male voice; 
- I would like the narrator of the videos to have a female voice.

6) If you were using an online system to help you develop skills to address these difficulties, which of the following would you like it to include? You may choose more than one answer.

- A short questionnaire to assess whether my difficulties can be addressed by this system so that I can proceed;

- A questionnaire to direct me to the right techniques for my personal circumstances;

- Tailor-made workshops where I can just click on the topic relevant to me and get to the techniques;

- A personal space where I can keep track of my activities and have all the relevant information and techniques recommended to me gathered together;

- The option to make a plan by when to familiarize myself with information and techniques and practice them with deadlines set by me;

- Receive reminders about my plan;

- To be able to check which of the recommended techniques I have familiarised myself with;

- To monitor whether I am doing better over time;

- A "diary space" where I can keep notes of which techniques I have used, how often, and which I found helpful and which not.

7) If you were using an online system to help you develop skills to address these difficulties, which of the following would you like it to include? You may choose more than one answer.

- To function in mobile devices, such as iPad and Blackberry playbook;

- To function on smartphones as a mobile application e.g. iPhone, Blackberry;

- Recommendations for self-help books;

- Forum to discuss with other students who have similar difficulties;

- Videos with testimonials from real people experiencing similar difficulties to mine;

- Information about my university's student support services or get professional help, if needed;

- A user support service, such as filling out a form or sending an email about technical difficulties with the site;

Other elements, please specify. 